\title{
An ATF4-mediated transcriptional adaptation of electron transport chain disturbance primes progenitor cells for proliferation in vivo
}

Sebastian Sorge ${ }^{1}$, Jonas Theelke ${ }^{1}$, Christian Altbürger ${ }^{2}$ and Ingrid Lohmann ${ }^{1 \ddagger}$

${ }^{1}$ Centre for Organismal Studies (COS) Heidelberg, Heidelberg University, Heidelberg, Germany

${ }^{2}$ Institute for Biology 1, University of Freiburg, Freiburg, Germany

¥Author for correspondence e-mail: ingrid.lohmann@cos.uni-heidelberg.de (I.L.)

Keywords: Drosophila, mitochondrial electron transport chain (ETC), ETC impairment, Notch pathway, ATF4, PERK, proliferation, UPR, ISR

Mailing address of corresponding author:

Ingrid Lohmann

University of Heidelberg

Im Neuenheimer Feld 230

$\mathrm{PH}: \quad+496221-545523$

D-69120 Heidelberg

FX: $\quad+496221-546424$

Germany

EM: ingrid.lohmann@cos.uni-

heidelberg.de 


\section{ABSTRACT}

The mitochondrial electron transport chain (ETC) enables many important metabolic reactions, like ATP generation and redox balance. While the vital importance of mitochondrial function is obvious, the cellular response to defects in mitochondria and in particular the modulation of signalling pathway outputs is not understood. Using the Drosophila eye as model, we show that the combination of Notch signalling and a mild attenuation of the ETC via knock-down of COX7a causes massive cellular overproliferation. The tumour like growth is caused by a transcriptional response through the elF2a-kinase PERK and ATF4, a stress-induced transcription factor, which activates the expression of many metabolic enzymes, nutrient transporters and mitochondrial chaperones. We find this stress adaptation to be beneficial for progenitor cell fitness upon ETC attenuation. Activation of the ATF4 mediated stress response renders cells sensitive to proliferation induced by the growth-promoting Notch or Ras signalling pathways, leading to severe tissue over-growth. In sum, our results suggest ETC function is monitored by the PERK-ATF4 pathway, a cellular adaptation hijacked by growth-promoting signalling pathways in situations of oncogenic pathway activity. 


\section{INTRODUCTION}

Controlling cell proliferation is one of the major challenges of multicellular life, both during phases of growth in developing organisms and phases of homeostatic cellreplenishment essential in adult animals. Lack of appropriate control can lead to severe disorders at any stage of life, including cancer. A century ago, Otto Warburg discovered a metabolic shift of cancer cells from respiration towards aerobic glycolysis and hypothesised that defective mitochondrial respiration triggers cancer development [1]. While mitochondria are not dysfunctional in many cancers, the switch to a glycolytic metabolism in cancer cells has been confirmed as a general feature of most cancers [2]. In addition, it has become clear more recently that proliferating mammalian cells generally rely on a glycolytic metabolism, presumably because high glycolytic flux allows for intermediates to be used for anabolic reactions, such as nucleotide biosynthesis [3]. Besides these intriguing findings, most of today's knowledge of how organisms control proliferation stems from the study of signalling pathways, which are frequently mutated in cancer (oncogenes and tumour suppressors) and causally linked to the uncontrolled growth of tumours [4]. In recent years, several studies have implicated a direct metabolic regulation of cell cycle progression $[5,6]$ and indirect effects on proliferation through reactive oxygen species (ROS) released by a dysfunctional mitochondrial electron transport chain $[6,7]$. In addition, it was shown that the nutritional status of imaginal cells, proliferating epithelial tissues in Drosophila that give rise to most external structures of the adult fly during metamorphosis, directly impacted on their proliferative behaviour [8]. Together, these studies highlight the importance of intersections between classical signalling pathways and metabolism in proliferating imaginal progenitors in vivo. Yet, most clonal assays focus on non-cell autonomous effects, omitting direct consequences of metabolic defects or adaptations on the physiology of (imaginal) progenitor cells and development of the tissues. 
Here, we used a tissue-specific GAL4-driver based labelling and manipulation approach targeting all eye progenitors to elucidate the interplay of metabolism and proliferation control. Compared to clonal analysis, this setup allowed us to study cellautonomous proliferation effects independently of competition between cells of different fitness, a process dominant in most clonal analyses. We found that eye progenitors autonomously activate a transcriptional stress response upon impairment of the mitochondrial electron transport chain, mediated through PERK and ATF4. We further demonstrated that this adaptation, which helps eye progenitors to follow their developmental program could be hijacked by growth-promoting pathways like Notch or Ras to enhance their proliferative effects. Our results suggest that ATF4-mediated transcriptional adaptation provides a cell-autonomous response to ETC defects, altering cellular behaviour through metabolic adaptation. 


\section{RESULTS}

\section{Mild reduction of COX7a enhances Notch-induced proliferation}

In order to identify new regulators of cell proliferation, we used RNA-seq expression data of a previously established eye tumour model in Drosophila, in which loss of the transcription factor Cut was shown to cooperate with Notch signalling to induce tumorigenesis [9] and tested down-regulated genes for tumour suppressor-like activity. To this end, we reduced their expression in the Drosophila eye by RNAi using the eyeless (ey)-GAL4 driver and screened for their ability to modify the well-described Notch-mediated mild over-proliferation induced by Delta over-expression ( $\left.\mathrm{DI}^{\mathrm{OE}}\right)[10]$ (Figures 1A, 1D and S1A). Among the 109 genes tested (Supplementary Table 1) we found one, the mitochondrial respiratory chain subunit Cytochrome C-oxidase subunit 7a $(C O X 7 a)$, which enhanced the slight over-proliferation induced by $\mathrm{DI}^{\mathrm{OE}}$ when its expression was reduced. In this context, we recovered over-proliferating eye imaginal discs (Figures 1D', 1E' and S1B), leading to strongly folded adult eyes (Figures 1D, 1E and $\mathrm{S} 1 \mathrm{~A}$ ), resembling tumorous tissue overgrowth. Interestingly, raising GAL4 activity using higher temperature $\left(29^{\circ} \mathrm{C}\right.$ instead of $\left.25^{\circ} \mathrm{C}\right)$ increased overgrowth of $\mathrm{DI}{ }^{\mathrm{OE}}$, COX7a ${ }^{R N A i}$ larval eye discs (Figures $1 \mathrm{E}^{\prime}$ and $1 \mathrm{~F}^{\prime}$ ), but also affected cell differentiation, as we observed a marked loss of ELAV-positive cells in the ventral domain of eye imaginal discs (Figures $1 \mathrm{E}^{\prime}$ and $1 \mathrm{~F}^{\prime}$ ), and reduced and malformed eyes in adult flies (Figures 1E and 1F). Strikingly, RNAi based interference with COX7a alone, which had been shown to cause general developmental defects and lethality due to attenuation of Complex 4 activity [11], negatively impacted on proliferation, as COX7a depleted Drosophila S2R+ cells (Figure S1D) were unable to divide (Figure S1C), and consistently the sizes of eye discs (Figures $1 \mathrm{~A}^{\prime}$ and $1 \mathrm{~B}^{\prime}$ ) and of adult eyes (Figures 1A, 1B and S1A) were reduced. Enhancement of RNAi further reduced eye size and also affected differentiation in COX7a ${ }^{\mathrm{RNAi}}$ eyes (Figures $1 \mathrm{C}$ and $\left.1 \mathrm{C}^{\prime}\right)$. Co-expression of the apoptosis inhibitor p35 [12], did not rescue eye size (Figures 1G-1I), excluding 
enhanced apoptosis induction as the primary cause of the smaller eye size phenotype in COX7a ${ }^{\mathrm{RNAi}}$ or over-proliferation of $\mathrm{DI}^{\mathrm{OE}}, \mathrm{COX} 7 \mathrm{a}^{\mathrm{RNAi}}$ animals. These results suggested that increased loss of COX7a in combination with Notch activation triggered overproliferation in eye progenitors, and additionally impaired either their capacity to enter the differentiation program or induced a switch towards a different (cuticle) fate.

In sum, our data showed that a mild disturbance of the ETC induced by COX7a knock-down modulated the Notch signalling pathway, thereby inducing the overproliferation of an epithelial tissue system, while stronger interference with COX7a affected in addition the differentiation of progenitor cells. As we were interested in understanding the modification of proliferation (but not of differentiation) by changes in ETC activity, we focused our analysis on the mild knock-down of COX7a at $25^{\circ} \mathrm{C}$.

\section{Notch and COX7a induce independent transcriptional responses that cooperate in proliferation control}

The Notch pathway affects cell behaviour primarily by controlling the transcriptional output via the processed Notch ${ }^{\text {intra }}$ domain interacting with the $\mathrm{Su}(\mathrm{H})$ transcription factor [13]. We assumed the COX7a mediated enhancement of over-proliferation in $\mathrm{DI}^{\mathrm{OE}}$, COX $7 \mathrm{a}^{\mathrm{RNAi}}$ animals to be caused by a modification of the Notch induced transcriptional response. Thus, we globally profiled transcriptome changes by performing microarray analysis of early L3 eye-antennal discs that were at the onset of differentiation. This analysis confirmed activation of generic and eye-specific Notch target genes, including Enhancer of split complex genes like $E(s p l) m 2, E(s p l) m 3$ and $E(s p l) m 7$ and eyegone (eyg), when the Notch pathway was activated by $\mathrm{DI}^{\mathrm{OE}}$ (Figure $2 \mathrm{~A}$ ), and showed that the tissue was not compromised by Delta over-expression, as stress or other pathway genes were not induced (Figures 2C, S2D, S2F). Interference with COX7a induced a completely different transcriptional response, which hardly overlapped with the changes caused by $\mathrm{DI}^{\mathrm{OE}}$ (Figures $2 \mathrm{~F}$ and $2 \mathrm{G}$ ). We found transcripts for several 
glycolytic enzymes including lactate dehydrogenase (LDH) (Figure 2D), amino acid and sugar transporters (Figure 2B), as well as mitochondrial chaperones (Figure 2C) increased in COX7a $\mathrm{a}^{\mathrm{RNAi}}$ but not in $\mathrm{DI}^{\mathrm{OE}}$ imaginal discs. Using a $L D H$-GFP enhancer trap [14] we confirmed LDH expression in L3 eye-antennal discs upon COX7a knockdown (either alone or in combination with $\mathrm{DI}^{\mathrm{OE}}$ ) (Figure $2 \mathrm{E}$ and $2 \mathrm{H}$ ). These results suggested that eye progenitors responded to Delta over-expression by over-activating the Notch pathway and mounted a specific stress-response upon knockdown of COX7a, without activating typical stress pathways like Nrf2 or JNK (Figures S2D - S2F). However in contrast to our expectations, we did not observe enhanced induction of COX7a ${ }^{\mathrm{RNAi}}$ or $\mathrm{DI}^{\mathrm{OE}}$ targets in $\mathrm{DI}{ }^{\mathrm{OE}}, \mathrm{COX} 7 \mathrm{a}^{\mathrm{RNAi}}$ eye discs (Figures 2A-2D), nor did we observe the induction of new targets (besides a few) in COX7a ${ }^{\mathrm{RNAi}}, \mathrm{DI}^{\mathrm{OE}}$ eye discs (Figure S2G). These results demonstrated that the $\mathrm{COX} 7 \mathrm{a}^{\mathrm{RNAi}}, \mathrm{DI}^{\mathrm{OE}}$ induced over-proliferation was not caused by the transcriptional cooperation of Notch and an unknown COX7a nuclear effector but that these two programs act independently.

We noticed however that food quality altered $\operatorname{COX} 7 \mathrm{a}^{\mathrm{RNAi}}$ induced phenotypes, as diets with reduced protein content enhanced over-proliferation of eye tissue in $\mathrm{DI}{ }^{\mathrm{OE}}$, COX7 $\mathrm{a}^{\mathrm{RNAi}}$ animals (Figures $\mathrm{S} 2 \mathrm{~B}$ and $\mathrm{S} 2 \mathrm{C}$ ) and promoted eye size reduction in COX7 $\mathrm{a}^{\mathrm{RNAi}}$ animals (Figure S2B), while over-proliferation of adult eyes in $\mathrm{DI}{ }^{\mathrm{OE}}$, COX7 $\mathrm{a}^{\mathrm{RNAi}}$ animals was absent on a pure yeast (high protein) diet (Figure S2B). And consistent with the enhancement of the phenotypic strength under nutrient restriction, many more targets were induced by $\mathrm{COX} 7 \mathrm{a}^{\mathrm{RNAi}}$ when animals were raised under poor diet conditions (472 vs. 115), while the majority of targets induced on normal food were confirmed (86/115) (Figure S2A). These results suggested that amino acid limitation directly altered eye progenitor cells response to COX7a knockdown through modulation of intracellular signalling or alternatively a dependence on systemic hormone signalling. 
Together, these results revealed that COX7a knock-down induced a transcriptional response independent of Notch via an unknown nuclear effector activating genes with diverse cellular functions.

\section{ATF4 mediates the nuclear response induced by ETC disturbance}

In order to uncover the pathway mediating the nuclear response induced by COX7a knock-down, we genetically screened for candidates able to modify the $\mathrm{DI}$, COX7 $\mathrm{a}^{\mathrm{RNAi}}$ over-proliferation phenotype. The induction of mitochondrial chaperones indicated that $\operatorname{COX} 7 \mathrm{a}^{\mathrm{RNAi}}$ cells were compromised and stressed, thus we tested many of the well-known stress-response or proliferation-inducing pathways, including JNK, Wnt, AMPK, Nrf2, and HIF1a. Although we observed a slight activation of the JNK pathway as evidenced by reporter lines and target genes (Figures S2D and S2E), none of these pathways was able to rescue $\mathrm{DI}^{\mathrm{OE}}, \mathrm{COX} 7 \mathrm{a}^{\mathrm{RNAi}}$-induced over-proliferation when their activity was reduced (data not shown). Thus, we excluded them as mediators of the combinatorial COX7a and Notch induced effects. Another stress-induced transcription factor adapting cells to various insults such as ER protein folding stress is Activating Transcription Factor 4 (ATF4; cryptocephal in Drosophila). Consistent with a possible involvement of ATF4, we identified the human ATF4 motif as the highestranking motif among the regulatory sequences of COX7a ${ }^{\text {RNAi }}$-induced genes $(22 / 114$; Figure 3A) using iRegulon prediction of motif enrichment [15]. Interestingly, in Drosophila $\mathrm{S} 2 \mathrm{R}^{+}$cells, ATF4 was shown to induce LDH and glycolytic enzymes upon ER stress [16], which we also found activated in eye discs (Figures 2D, 2E and 2H), and in mammals, ATF4 regulates various amino acid transporters homologous to the ones we recovered in our in vivo transcriptome profiling [17]. In order to test a potential involvement of ATF4, we performed knock-down experiments in $\mathrm{DI}^{\mathrm{OE}}$, COX7a $\mathrm{a}^{\mathrm{RNAi}}$ animals and found that down-regulation of ATF4 completely rescued the overproliferation in larval discs and adults (Figures $3 C, 3 E$ and $3 G$ ), resembling 
phenotypically $\mathrm{DI}^{\mathrm{OE}}$ eyes (Figure 1D). Using an antibody against ATF4 [18] we detected transient ATF4 expression upon COX7a ${ }^{\mathrm{RNAi}}$ in early L3 eye progenitors anterior to the morphogenetic furrow, while control and late L3 eye discs lacked detectable ATF4 protein expression (Figures $3 \mathrm{C}$ and $\mathrm{S} 3 \mathrm{~A}$ ). Importantly, the activation of the vast majority of COX7a $\mathrm{R}^{\mathrm{RNA}}$ targets (431/472) required ATF4 function, as these targets were not induced in COX7a ${ }^{\mathrm{RNAi}}, \mathrm{ATF} 4^{\mathrm{RNAi}}$ discs (Figure S3D). Likewise, the majority of target genes induced by the combination of $\mathrm{DI}^{\mathrm{OE}}$ and $\mathrm{COX} 7 \mathrm{a}^{\mathrm{RNAi}}$ required ATF4 (Figure 3B). These target genes include all COX7a $\mathrm{a}^{\mathrm{RNAi}}$-induced genes shown in Figures 2B-2D, both in the presence (Figure 3D) or absence (Figure S3C) of $\mathrm{DI}^{\mathrm{OE}}$. The LDH-GFP reporter acted as a bona fide reporter for ATF4 activity, as GFP expression was undetectable in COX7a ${ }^{\text {RNAi }}$, ATF4 ${ }^{\text {RNAi }}$ eye discs (Figure 3F).

We next sought to understand which of the ATF4 targets enhanced proliferation and screened several candidates in the $\mathrm{DI}^{\mathrm{OE}}$, COX7a $\mathrm{R}^{\mathrm{RNAi}}$ background. Amongst the COX7 $\mathrm{a}^{\mathrm{KD}}$-induced genes we identified a single gene, called Irbp18, whose knockdown rescued over-proliferation, qualitatively and quantitatively similar to ATF4 ${ }^{\text {RNAi }}$ (Figure 3E). Irbp18 encodes the homologue of C/EBP $\gamma$ and had been shown to be one of two heterodimeric binding partners for ATF4 [19], which was shown before to regulate most ATF4-dependent target genes of the integrated stress response (ISR) together with ATF4 in mouse cells [20]. Screening of genes with direct metabolic functions did not reveal a single gene that was similarly required for over-proliferation as the upstream regulators. At best, we found that the knockdown of pathetic (path), a gene encoding an amino acid transporter or sensor [21], and the Drosophila homolog of BCAT1, an branched-chain amino acid biosynthetic enzyme, slightly attenuated over-proliferation (Figure S3E). Thus, we assume the induction of a complex network of ISR genes to be required to enhance Notch-mediated over-proliferation. 
Taken together, these results demonstrated that ATF4 and C/EBP $\gamma$ acted as the main transcriptional effectors downstream of COX7a-mediated mild ETC disturbance and suggested that multiple ATF4 and Notch induced target genes cooperate in eye progenitor over-proliferation.

\section{PERK mediates ATF4 activation upon ETC disturbance}

In a next step, we wanted to elucidate how ATF4 becomes activated upon COX7a knock-down. ATF4 is known to be translated only under conditions of elF2 $\alpha$ phosphorylation, owing to the existence of two $\mu$ ORFs (open reading frames) in its 5'UTR that block translation of the ATF4 ORF under normal conditions [22]. The Drosophila genome encodes two elF2 $\alpha$ kinases, GCN2 and PERK. GCN2 is activated by uncharged tRNAs, phosphorylating elF2 $\alpha$ to slow down translation when amino acids are lacking [22]. As the $\mathrm{DI}$ acid poor diet, the activation of GCN2 seemed the most likely explanation. However, we found that GCN2 knockdown did not rescue over-proliferation in by $\mathrm{DI}^{\mathrm{OE}}, \mathrm{COX} 7 \mathrm{a}^{\mathrm{RNAi}}$ animals, but induced higher larval and pupal lethality under nutrient restriction (Figure 4A). As these effects are largely independent of the genetic context, we assumed that GCN2-mediated translational repression via elF2 $\alpha$ phosphorylation was required for transient adaptation of the developing tissue to a lack of amino acids. The second elF2 $\alpha$-kinase, PERK, is known for its role in mediating a transcriptional response through ATF4 as a result of ER protein folding stress [22,23], and interestingly, PERK knock-down completely rescued the over-proliferation in $\mathrm{DI}^{\mathrm{OE}}, \mathrm{COX} 7 \mathrm{a}^{\mathrm{RNAi}}$ animals (Figure 4A). This result suggested that PERK is activated upon COX7a knock-down, mediating elF2 $\alpha$ phosphorylation and consequently ATF4 translation. As expected, PERK $^{\text {RNAi }}$ abolished the induction of ATF4 (Figure 4B), indicating that PERK acts upstream of ATF4. 
PERK is an ER-resident kinase that mediates one branch of the unfolded protein response of the endoplasmic reticulum $\left(U P R^{\mathrm{ER}}\right)$ [23]. However, the ER chaperones BiP (Hsc70-3 in Drosophila) and GRP94 (Gp93 in Drosophila) as well as other well known targets of the Ire1/Xbp1 and ATF6 branches of the UPR ${ }^{E R}$ [24], were not induced according to our in vivo transcriptome profiling (Figure S4A). Consistently, the Xbp1EGFP reporter [25] specific for this branch of the UPR ${ }^{\mathrm{ER}}$ was not activated by COX7a knock-down at all (Figure S4B) and knock-down of ATF6 was not able to rescue the $\mathrm{DI}^{\mathrm{OE}}, \mathrm{COX} 7 \mathrm{a}^{\mathrm{RNAi}}$ induced over-proliferation (Figure S3E). Together, these results showed that the UPR ${ }^{\mathrm{ER}}$ is not activated upon COX7a knockdown, but suggest a function of PERK independent of canonical ER stress.

The Drosophila genome encodes three isoforms of PERK, differing only in the Nterminus of the protein. Isoform A contains the expected N-terminal signal peptide for ER import, but we found isoform B to carry a potential mitochondrial import sequence according to MitoProtll prediction [26]. Isoform C contains no obvious signal peptide at all and is hardly expressed during development. To assess the potential mitochondrial localisation of isoform $B$, we fused the N-termini of PERK-A and PERK-B with EGFP and expressed these constructs in Drosophila S2R+ cells. As predicted, PERK-B ${ }^{\mathrm{N}-\text { term }}$ EGFP showed a filamentous signal that overlapped with the mitochondrial dye TMRM (Figure 4C), while PERK-A ${ }^{\mathrm{N}-\text {-erm }}$-EGFP showed a discrete labelling of the endomembrane system and did not co-localise with TMRM (Figure 4C).

Taken together, these results suggested that the PERK isoform B, which is targeted to mitochondria, acts as the elF2 $\alpha$ kinase activated upon COX7a knock-down, eliciting a transcriptional response through ATF4 that activated target genes of the Integrated Stress Response and the mitochondrial Unfolded Protein Response.

ATF4-mediated adaptation is a general feature of ETC disturbance and enhances proliferation of other oncogenic pathways 
Our results showed that ETC disturbance through COX7a knock-down activated the PERK-elF2 $\alpha-A T F 4$ axis, thereby inducing target genes of the ISR and UPR ${ }^{\mathrm{mt}}$. As would be expected from a partial loss of ETC function, eye progenitors were compromised in their normal development despite the stress response, and these defects were further increased when the stress response was inhibited by ATF4 ${ }^{\text {RNAi }}$ (Figure S3B). In contrast to this situation, activation of the Notch pathway by $\mathrm{DI}^{\mathrm{OE}}$ genetically interacted with ETC dysfunction to induce hyper-proliferation (Figures 1A-1B and 1D-1E), arguing that ATF4-mediated adaptation allows cells with elevated Notch signalling to further increase their rate of proliferation. To extend these findings beyond COX7a, we asked whether interference with other subunits of ETC complexes would cause similar phenotypes and ATF4 induction. In total we found 12 of 15 subunits (15/18 RNAi constructs) to cause similar or stronger phenotypes as $\mathrm{COX} 7 \mathrm{a}^{\mathrm{RNAi}}$ during eye development. All constructs targeting ETC Complex 1 or 4 induced an eye phenotype, while constructs targeting ETC Complex 2 showed no effects and only some constructs targeting Complex 3 resulted in eye phenotypes (Supplementary Table 2). The phenotypes induced were either very similar to $\mathrm{COX} 7 \mathrm{a}^{\mathrm{RNAi}}$ or showed severely reduced eyes and head malformations (Figure 5A), stronger than COX7a under enhanced knock-down conditions (Figure 1C and 1F). Importantly, we did not find any correlation of phenotypic classes with ETC complexes. To test for ATF4 induction, we used the LDH-GFP reporter and found that 3 of 3 Complex 1 subunits, 3 of 4 Complex 4 subunits and 1 of 2 Complex 3 subunits induced LDH-GFP expression (Figure 5B). Combined, these results strongly argued that knock-down of subunits of the large ETC Complexes 1,3 and 4 induced an ATF4 response similar to $\mathrm{COX} 7 \mathrm{a}^{\mathrm{RNAi}}$. Though developmental phenotypes (reduced eyes or near-complete ablation of the eye primordium) and ATF4 induction are both common amongst the subunits we tested, the strength of these two phenotypes did not correlate well, indicating that cellular defects or stress might not necessarily be the signal activating ATF4 through PERK. 
After having established that knock-down of many subunits of different ETC complexes caused COX7a $a^{\mathrm{RNAi}}-$ like phenotypes, we sought to investigate whether the pro-proliferative genetic interaction with Notch signalling might be a more common feature as well. To this end, we used eye progenitors expressing oncogenic Ras ${ }^{\mathrm{G} 2 \mathrm{~V}}$ $\left(\operatorname{Ras}^{\mathrm{v} 12}\right)$, a common mutation in colon and lung carcinomas [27]. Ras ${ }^{\mathrm{v} 12}$ eyes are hyperproliferative and show a characteristic outgrowth on the dorsal-anterior border of the eye as well as necrotic ommatidia (Figure 5C). Knock-down of COX7a dramatically increased eye size in age-matched larval discs (Figure 5D) and in adult survivors (Figure 5C and S5C). This effect was dependent on ATF4, as simultaneous interference with ATF4 reduced the over-proliferative phenotype (Figure 5C and S5C).

Together, these results demonstrated that reduced expression of ETC subunits caused an ATF4-mediated transcriptional response that in combination with growthpromoting signalling pathways like Notch or Ras leads to oncogenic over-proliferation of tissues. 


\section{DISCUSSION}

We showed here that genetically induced disturbance of ETC complexes resulted in a metabolic shift typical for mitochondrial impairment (Figures S5D-5F) $[28,29]$ and activated an ATF4 dependent stress response. The in vivo transcriptional adaptation we present here confirmed the regulation of LDH and glycolytic enzymes as shown in Drosophila cultured cells [16] and further includes several targets shown to be ATF4 target genes in mammalian models $[30,31]$. Our results showed that the elF2 $\alpha-k i n a s e$ PERK, so far only described for its role in mediating one branch of the $U P R^{E R}$, is the upstream kinase phosphorylating elF2 $\alpha$, thereby inducing ATF4 translation in response to mitochondrial ETC disturbance. Mitochondrial ETC ${ }^{K D}$ specifically activated PERK, while other branches of the UPR ${ }^{E R}$ are non-responsive. PERK activation upon mitochondrial defects was recently observed in Drosophila models of Parkinson's disease [32] and was explained by the authors by its preferential localisation to mitochondria-associated ER membranes, which might make PERK more susceptible to a local stress signal. We have now shown here that Drosophila PERK isoform B contains a mitochondrial signal peptide, which is not found in mammalian PERK isoforms. The current evidence suggests that this Drosophila PERK isoform is imported into mitochondria, where it becomes degraded. Upon mitochondrial stress, import is disturbed and PERK accumulates in the cytoplasm, where it becomes activated. A similar strategy to monitor mitochondrial stress has been described in C. elegans, where an ATF4-like transcription factor is targeted to and degraded in mitochondria [33].

In addition to canonical ATF4 target genes, we observed ATF4-dependent upregulation of mitochondrial chaperones, a response classically referred to as the mitochondrial unfolded protein response $\left(U P R^{\mathrm{mt}}\right)$. In $C$. elegans, mitochondrial chaperone induction upon stress is mediated by Atfs-1 [33], while the mammalian $U_{P R}{ }^{m t}$ has been shown to be regulated by the evolutionary related transcription factor 
ATF5 [34]. Our data now showed that Drosophila ATF4 is required cell-autonomously for induction of mitochondrial chaperones upon ETC subunit knock-down, implying that Drosophila might represent the evolutionary ancestral ISR-UPR ${ }^{\mathrm{mt}}$ regulation through a single ATF4-like transcription factor.

Previously, inhibition of mtDNA replication [35] and chemicals inhibiting different mitochondrial processes [31] have linked mitochondrial dysfunction to an ATF4 response. Our results presented here focus on the genetic knockdown of the nuclearencoded ETC subunit 7a of Complex 4, but we have confirmed several other subunits of Complex 1,3 and 4 to cause similar phenotypes and ATF4 induction in vivo, suggesting that genetic loss or reduction of individual subunits induces a common response. As upstream metabolic reactions did not elicit the same adaptation (data not shown), it appears unlikely that a general defect in metabolism would be the primary trigger of the ATF4 response. Therefore, our results are in agreement with the interpretation of Yoneda and colleagues [36], who suggested that the C. elegans $U_{P R}{ }^{m t}$ is triggered in response to an overload of the mitochondrial protein folding machinery. This interpretation suggests that the ATF4 response is induced before detrimental dysfunction or damage occurs, possibly explaining why we failed to detect dysfunction or alterations of mitochondrial morphology (Figures S5A and S5B) in our model.

A novel finding presented in this study was the discovery that ATF4-mediated transcriptional adaptation allowed eye progenitors to increase their proliferation in response to signals from the Notch and Ras pathways. The primary questions arising from this genetic interaction is how these signalling pathways can overcome the apparent cellular stress and reduction in proliferation and then use the ATF4-mediated transcriptional adaptation for massively increased proliferation. A previous study showed that COX5a mutant clones activated a mitotic checkpoint through AMPK activation and reduced CycE expression [6]. Our cell culture metabolome studies 
suggested that AMP levels are indeed increased (Figure S5F). Furthermore, we observed a rescue of the COX7a knockdown induced small eye phenotype upon expression of CycE (data not shown), arguing that this phenotype might be primarily caused by a failure of cells to enter S-phase. As the Notch pathway had been shown to directly up-regulate CycE in Drosophila wing imaginal discs [37], $\mathrm{DI}{ }^{\mathrm{OE}}$ in our model might simply overcome the checkpoint activated through rising AMP levels. In a second step, Notch signalling would be able to use the re-configured set of metabolic enzymes to drive cells faster through the cell cycle. Our transcriptome data imply that the differential capacity to take up nutrients from the hemolymph (such as amino acids) and the way they are used by the cells could be at the heart of this phenotype.

The cooperation between ATF4 target genes and the Notch or Ras pathways in Drosophila imaginal progenitors raised the intriguing possibility that these or other oncogenic pathways could benefit from ATF4 activity in human cancers. Over the last decades it had been demonstrated that human cancer cells are exposed to several stresses, including hypoxia, ROS or limitations in nutrient availability $[38,39]$. In order to survive these conditions and maintain their growth capacity, tumour cells activate responses like the HIF1a transcription factor axis [40]. Though less well studied, an involvement of ATF4 in cancer has been suggested mostly through work with cultured cells (for review see [41]). We analysed gene expression in human cancer samples of TCGA datasets using Cancer-RNAseq-Nexus [42] and the human protein pathology atlas [43], and found that many of the well characterised direct ATF4 targets [30] are up-regulated in a variety of cancer types. Most strikingly, transcriptomes of Kidney renal clear cell carcinoma showed progressive induction of ATF4 and many of its direct targets (EIF4EBP1, ASNS, TRIB3, VEGFA) on the transcriptional level, which strongly correlated with a poor prognosis in this type of cancer. In sum, our data suggest that the ATF4-mediated ISR is used by cancer cells to adapt their metabolic repertoire, thereby sustaining fast growth under increasingly unfavourable conditions. 
bioRxiv preprint doi: https://doi.org/10.1101/425744: this version posted September 24,2018 . The copyriaht holder for this preprint (which was not certified by peer review) is the author/funder, who has granted bioRxiv a license to display the preprint in perpetuity. It is made available under aCC-BY-NC-ND 4.0 International license. 


\section{METHODS}

\section{Fly stocks and husbandry}

Flies were reared on a standard corn meal food recipe (cornmeal, barley malt, molasses, yeast extract, soy flour, propionic acid, Nipagin) at room temperature. Experimental crosses were carried out at $25^{\circ} \mathrm{C}$ unless otherwise noted. A reduced protein diet was prepared according to [8], with $20 \mathrm{~g}$ fresh yeast per litre food and with $0.6 \%(\mathrm{v} / \mathrm{v})$ propionic acid instead of Nipagin/Nipasol.

We used eyeless-Gal4 from [10] as the main Gal4-driver, but confirmed the primary phenotypes with the similar line ey3.5-Gal4 (BL-8220) and the unrelated driver so-Gal4 (BL-26810). RNAi lines were from Bloomington (TRiP libraries) or Vienna (KK library) stock centres. Whenever possible, phenotypes were confirmed by two independent RNAi lines (done for COX7a, COX5a, ND75). LDH-GFP was described in [14], TREGFP in [44] and Xbp1-EGFP in [25].

Rescue experiments in the ey>Delta,COX7aRNAi background were carried out with virgins from the triple transgenic stock (ey-Gal4, UAS-Delta, UAS-COX7aRNAi/CyOTbRFP) crossed to males carrying UAS-RNAi or UAS-OE transgenes. As controls, UAS-GFP $^{\text {nls }}$, UAS-mCD8-GFP, UAS-EGFP-RNAi or UAS-mCherry-RNAi were used. An average cross consisted of 10 to 12 virgins, mated with 6 to 10 males. Females were allowed to lay eggs for 1 to 2 days in fly food vials $\left(10 \mathrm{ml}\right.$ food on $5.3 \mathrm{~cm}^{2}$ surface). To assess effects of crowding and for some crosses, freshly hatched L1 larvae were transferred by hand from apple-juice plates to food vials in defined numbers.

\section{Immunofluorescence}

Antibody staining of larval eye-antennal discs was carried out according to standard procedures. In brief, larvae of corresponding stage (primarily early or late L3) were picked from the vial, collected, rinsed and dissected in PBS. Heads, usually consisting of mouth hooks, cephalopharyngeal skeleton, eye-antennal discs and CNS, were transferred to tube with PBS (with $0.01 \%$ Tween-20) on ice and then fixed with $4 \%$ 
para-formaldehyde for 18 minutes at room temperature on a nutator. Blocking was done with $1 \%$ blocking reagent (PerkinElmer) in PBT $(0.1 \%$ Tween-20). Primary antibodies used were from DSHB (rat anti-ELAV 1:300, ms anti-Dachshund 1:300, ms anti-Wingless 1:40), Cell Signalling (rab anti-Casp3 1:200), Abcam (ms anti-ATP5a 1:500), SantaCruz (rab anti-PH3 1:1000) and Min-Ji Kang (gp anti-ATF4 1:66). Secondary antibodies were from Jackson Immunoresearch or Molecular Probes. Vectashield with DAPI was used as mounting medium.

\section{Microscopy and Image analysis}

Larval discs were imaged on a Leica TCS SP8 confocal microscope. All experiments directly comparing antibody labelling of discs of different genotypes were dissected alongside, stained and imaged under identical settings (using master mixes for IF and identical laser and scanner settings). Images or confocal stacks were processed with the ImageJ distribution Fiji and Adobe Photoshop CS6. Generally, contrast was not enhanced. In some cases, rolling ball background subtraction was used. Most images shown are sum or maximum or sum projections of confocal stacks. Quantifications were done with Fiji: mean intensities were measured within rectangles centred at the equator of the eye field of sum projections or individual focal planes. Areas were manually outlined, taking folded parts of the tissue into consideration.

Whole adult flies were photographed on a Zeiss Discovery V12 stereo microscope with a Zeiss HR3 camera.

\section{Transmission electron microscopy}

Transmission electron microscopy (TEM) was carried out on late L3 larval eyeantennal discs. Eye-antennal discs were dissected in 1xPBS from third-instar larvae and fixed in $1.5 \%$ Paraformaldehyde and $0.2 \%$ Glutaraldehyde (GA) solved in $0.1 \mathrm{M}$ Cacodylate buffer at $4^{\circ} \mathrm{C}$ over night. After four washing steps for 10 minutes with $0.1 \mathrm{M}$ Cacodylate buffer the discs were fixed again with $2 \%$ Osmium in $0.1 \mathrm{M}$ Cacodylate buffer for two hours at room temperature. Afterwards the discs were washed with $0.1 \mathrm{M}$ 
Cacodylate buffer for 10 minutes twice and twice for 10 minutes with water (bidest). For raising the contrast of the samples the discs were incubated in $1 \%$ Uranyl acetate in water (bidest) at $4^{\circ} \mathrm{C}$ over night. After contrasting the discs were washed four times with water (bidest) and the water was subsequently stepwise replaced by ethanol. After five minutes of incubation in $100 \%$ Propylene oxide, the discs were incubated for an hour in 1:3 Epon/Propylene oxide, an hour in 1:1 Epon/Propylene oxide and finally replaced by pure Epon. For polymerisation the Epon was again replaced by fresh Epon and incubated for four hours at room temperature. The discs were transferred to beem capsules in Epon and the polymerization took place in an oven at $60^{\circ} \mathrm{C}$. The samples were analysed with a Jeol JEM-1400 electron microscope (JEOL Deutschland, Freising) operated at $80 \mathrm{KV}$.

\section{RNA isolation and Microarray analysis}

Total RNA was isolated from 20 to 30 early L3 eye-antennal discs using TRIzol (Invitrogen) and the Direct-Zol MicroPrep kit (ZymoResearch). 50ng of total RNA was used for processing with Affymetrix GeneChip® 3' IVT Express Reagent Kit (1st Microarray) or GeneChip® 3' IVT PLUS Reagent Kit (2nd Microarray). cRNA was hybridised to Affymetrix Drosophila Genome2.0 chips. The EMBL GeneCore Facility carried out IVT, hybridisation and chip imaging. Data was analysed with Affymetrix Software using the RMA normalisation algorithm. All fold-changes and significance (ANOVA p-value) reported in the study are based on this analysis.

\section{Analysis of metabolites}

Free amino acids and thiols were extracted from $1 * 10^{6} \mathrm{~S} 2 \mathrm{R}+$ cells with $0.3 \mathrm{ml}$ of 0.1 $\mathrm{M} \mathrm{HCl}$ in an ultrasonic ice-bath for $10 \mathrm{~min}$. The resulting extracts were centrifuged twice for $10 \mathrm{~min}$ at $4^{\circ} \mathrm{C}$ and $16.400 \mathrm{~g}$ to remove cell debris. Amino acids were derivatised with AccQ-Tag reagent (Waters) and determined as described in [45]. Total glutathione was quantified by reducing disulfides with DTT followed by thiol derivatisation with the fluorescent dye monobromobimane (Thiolyte, Calbiochem). For 
quantification of GSSG, free thiols were first blocked by NEM followed by DTT reduction and monobromobimane derivatisation. GSH equivalents were calculated by subtracting GSSG from total glutathione levels. Derivatisation was performed as described in [46]. UPLC-FLR analysis was carried out using an Acquity H-class UPLC system. Separation was achieved with a binary gradient of buffer A (100 mM potassium acetate, $\mathrm{pH} 5.3$ ) and solvent $\mathrm{B}$ (acetonitrile) with the following gradient: 0 min $2.3 \%$ buffer $\mathrm{B} ; 0.99 \min 2.3 \%, 1 \min 70 \%, 1.45 \min 70 \%$, and re-equilibration to $2.3 \% \mathrm{~B}$ in $1.05 \mathrm{~min}$ at a flow rate of $0.85 \mathrm{ml} \mathrm{min}^{-1}$. The column (Acquity BEH Shield RP18 column, $50 \mathrm{~mm} \times 2.1 \mathrm{~mm}, 1.7 \mu \mathrm{m}$, Waters) was maintained at $45^{\circ} \mathrm{C}$ and sample temperature was kept constant at $14{ }^{\circ} \mathrm{C}$. Monobromobimane conjugates were detected by fluorescence at $480 \mathrm{~nm}$ after excitation at $380 \mathrm{~nm}$ and quantified using ultrapure standards (Sigma). Determination of organic acids was adapted from [47]. In brief, $1 * 10^{6} \mathrm{~S} 2 \mathrm{R}+$ cells per sample were extracted in $0.2 \mathrm{ml}$ ice-cold methanol with sonication on ice. $50 \mu \mathrm{l}$ extract was mixed with $25 \mu \mathrm{l} 140 \mathrm{mM}$ 3-Nitrophenylhydrazine hydrochloride (Sigma-Aldrich), $25 \mu \mathrm{l}$ methanol and $100 \mu \mathrm{l} 50 \mathrm{mM}$ Ethyl-3-(3dimethylaminopropyl) carbodiimide hydrochloride (Sigma-Aldrich) and incubated for 20 $\min$ at $60^{\circ} \mathrm{C}$. Separation was carried out on the above described UPLC system coupled to a QDa mass detector (Waters) using an Acquity HSS T3 column (100 mm x $2.1 \mathrm{~mm}$, $1.8 \mu \mathrm{m}$, Waters) which was heated to $40^{\circ} \mathrm{C}$. Separation of derivates was achieved by increasing the concentration of $0.1 \%$ formic acid in acetonitrile $(B)$ in $0.1 \%$ formic acid

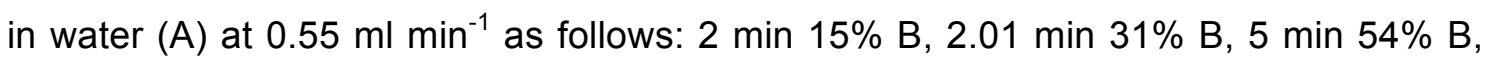
$5.01 \mathrm{~min} 90 \% \mathrm{~B}$, hold for $2 \mathrm{~min}$, and return to $15 \% \mathrm{~B}$ in $2 \mathrm{~min}$. Mass signals for the following compounds were detected in single ion record (SIR) mode using negative detector polarity and $0.8 \mathrm{kV}$ capillary voltage: Lactate $(224.3 \mathrm{~m} / \mathrm{z} ; 25 \mathrm{~V} \mathrm{CV})$, malate $(403.3 \mathrm{~m} / \mathrm{z} ; 25 \mathrm{~V} \mathrm{CV})$, succinate $(387.3 \mathrm{~m} / \mathrm{z} ; 25 \mathrm{CV})$, fumarate $(385.3 \mathrm{~m} / \mathrm{z} ; 30 \mathrm{~V})$, citrate $(443.3 \mathrm{~m} / \mathrm{z} ; 10 \mathrm{~V})$, pyruvate $(357.3 \mathrm{~m} / \mathrm{z} ; 15 \mathrm{~V})$ and ketoglutarate $(550.2 \mathrm{~m} / \mathrm{z} ; 25 \mathrm{CV})$. Data acquisition and processing was performed with the Empower3 software suite 
(Waters). The Metabolomics Core Technology Platform at the University of Heidelberg performed Metabolomic analysis.

\section{Cell culture}

Drosophila S2R+ cells were cultured in Schneider's medium (Gibco) with 10\% FBS (Gibco). COX7a knockdown in S2R+ cells was done with in vitro transcribed dsRNA using a PCR template (targeting the identical sequence as the in vivo RNAi line). Cells were incubated with the dsRNA in serum-free medium for 45 minutes. Afterwards, serum concentration was adjusted to $10 \%$ again. Knockdown efficiency was monitored at 4 or 7 days after treatment by qPCR from TRIzol-extracted total RNA. For transient transfections, Qiagen Effectene Transfection Reagent was used. Constructs were constitutively expressed from an actin promoter (pAC5.1_DEST, gift of M. Boutros). Live-imaging was carried out one or two days post-transfection in glass-bottom dishes (MatTek). 


\section{AUTHOR CONTRIBUTIONS}

S.S. conceived the study, designed, performed and interpreted most experiments, supervised and worked with J.T. und C.A. and wrote the paper with I.L. J.T. performed and interpreted experiments on COX7a knockdown in cultured $\mathrm{S} 2 \mathrm{R}+$ cells and performed experiments on food dependency of COX7a phenotypes. C.A. assisted in a primary RNAi screen, designed and performed the TEM experiment and helped with initial experiments. I.L. conceived the study, assisted in designing and interpreting experiments, wrote the paper with S.S., obtained funding to support the study DFG (Excellence Cluster "CellNetworks/EcTop6). S.S. obtained a PhD fellowship from HBIGS.

\section{ACKNOWLEDGMENTS}

We thank Jelena Pistolic and Vladimir Benes of EMBL GeneCore for the Microarray analysis. We thank the Metabolomics Core Technology Platform of the Excellence cluster "CellNetworks" (University of Heidelberg) and the Deutsche Forschungsgemeinschaft (grant ZUK 40/2010-3009262) for support with HPLC-based metabolite quantification. We thank Steffi Gold, as well as Stefan Hillmer at the Heidelberg University Electron Microscopy Core Facility (EMCF), for their help with the EM component of the work. Finally, we are indebted to Min Ji Kang, Stefanie Schirrmeier, Michael Boutros, Aurelio Teleman and Ana Gomez Barata for fly lines or reagents. We would also like to thank A. Teleman, J. Friedrich, P. Pinto and K. Domsch for carefully reading the manuscript and N. Trost for help with the GO term analysis. This work was supported by the Excellence Cluster CellNetworks (EcTop6) and a HBIGS PhD fellowship to S.S. We apologize to all whose work was not cited due to space limitations. 


\section{FIGURE LEGENDS}

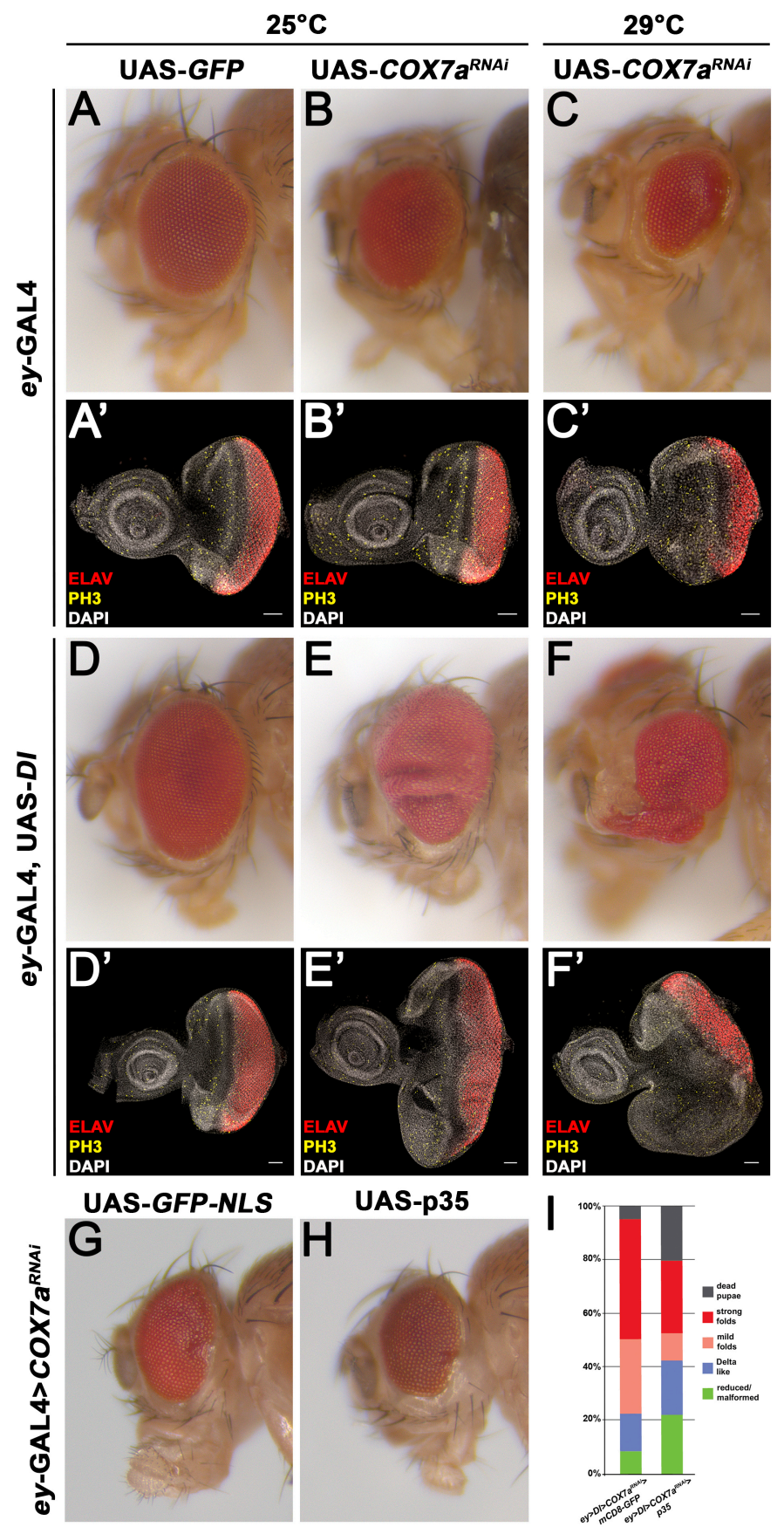

Figure 1: Reduction of COX7a enhances Notch-induced proliferation.

A-F Adult eyes of the indicated genotypes. Animals were reared at $25^{\circ} \mathrm{C}(\mathrm{A}, \mathrm{B}, \mathrm{D}, \mathrm{E})$ or $29^{\circ} \mathrm{C}$ (C, F) on standard fly food. COX7a knock-down reduced adult eye size in a dose-dependent manner (compare B, C and control A). Eyes of Delta over-expressing animals (D) were elongated along the dorso-ventral axis, due to increased proliferation of the ventral compartment. Knock-down of COX7a in the Delta background $(E)$ increased eye size and led to 
folding of the flat epithelium. Adult survivors at $29^{\circ} \mathrm{C}$ exhibited small, malformed eyes and head capsule $(F)$.

A'-F' Sum-projections of larval late L3 eye-imaginal discs of the indicated genotypes. Eye discs are stained for ELAV (red, labelling photoreceptors), phospho-Histone 3 (PH3) (yellow, labelling mitotic cells) and DAPI (white, labelling nuclei). Animals were reared at $25^{\circ} \mathrm{C}\left(\mathrm{A}^{\prime}, \mathrm{B}^{\prime}, \mathrm{D}^{\prime}, \mathrm{E}^{\prime}\right)$ or $29^{\circ} \mathrm{C}\left(\mathrm{C}^{\prime}, \mathrm{F}^{\prime}\right)$ on standard fly food. At $29^{\circ} \mathrm{C}\left(\mathrm{C}^{\prime}\right)$, dividing cells in the first mitotic wave (anterior to the morphogenetic furrow) and second mitotic wave (posterior o the morphogenetic furrow) appeared reduced. Delta over-expressing discs (D') show an enlarged ventral compartment. Knock-down of COX7a in the Delta background ( $\left.E^{\prime}\right)$ substantially increased size of the epithelium and showed a high density of proliferating cells in the ventral domain, where the progression of differentiation (ELAV, red) appeared to be slowed down. At $29^{\circ} \mathrm{C}$, heavily overgrown larval discs were recovered $\left(F^{\prime}\right)$, showing strong defects of cells to enter differentiation in the ventral compartment.

G, $\mathbf{H}$ Adult eyes from offspring of crosses of ey>COX7a ${ }^{R N A i}$ females with UAS-GFP ${ }^{N L S}$ males (G) as control or UAS-p35 males $(\mathrm{H})$ to inhibit apoptosis. Eye size was reduced in the absence of apoptosis, showing that cell death itself is not the reason for the small eye phenotype. Larvae were reared at $25^{\circ} \mathrm{C}$ under nutrient restriction.

I Quantification of adult eye phenotypes from offspring of crosses of ey>Delta>COX7a ${ }^{R N A i}$ females with UAS-mCD8-GFP or UAS-p35 males. Inhibition of apoptosis through p35 expression did not inhibit over-proliferation. Larvae were reared at $25^{\circ} \mathrm{C}$ under nutrient restriction.

Anterior is to the left, dorsal is up, scale bar represents $50 \mu \mathrm{m}$ in all microscope images. See also Fig S1. 


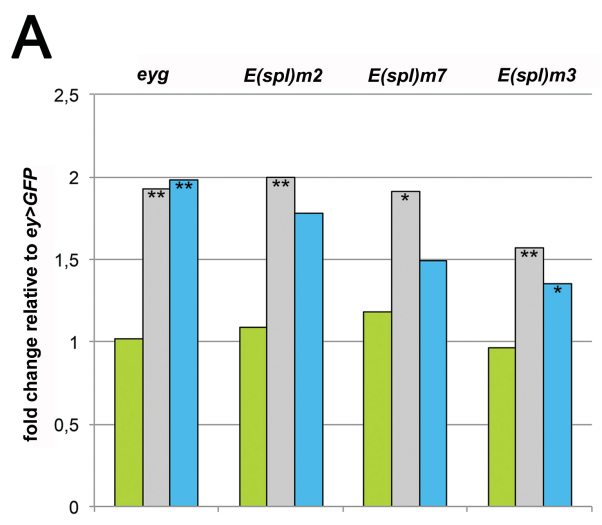

B
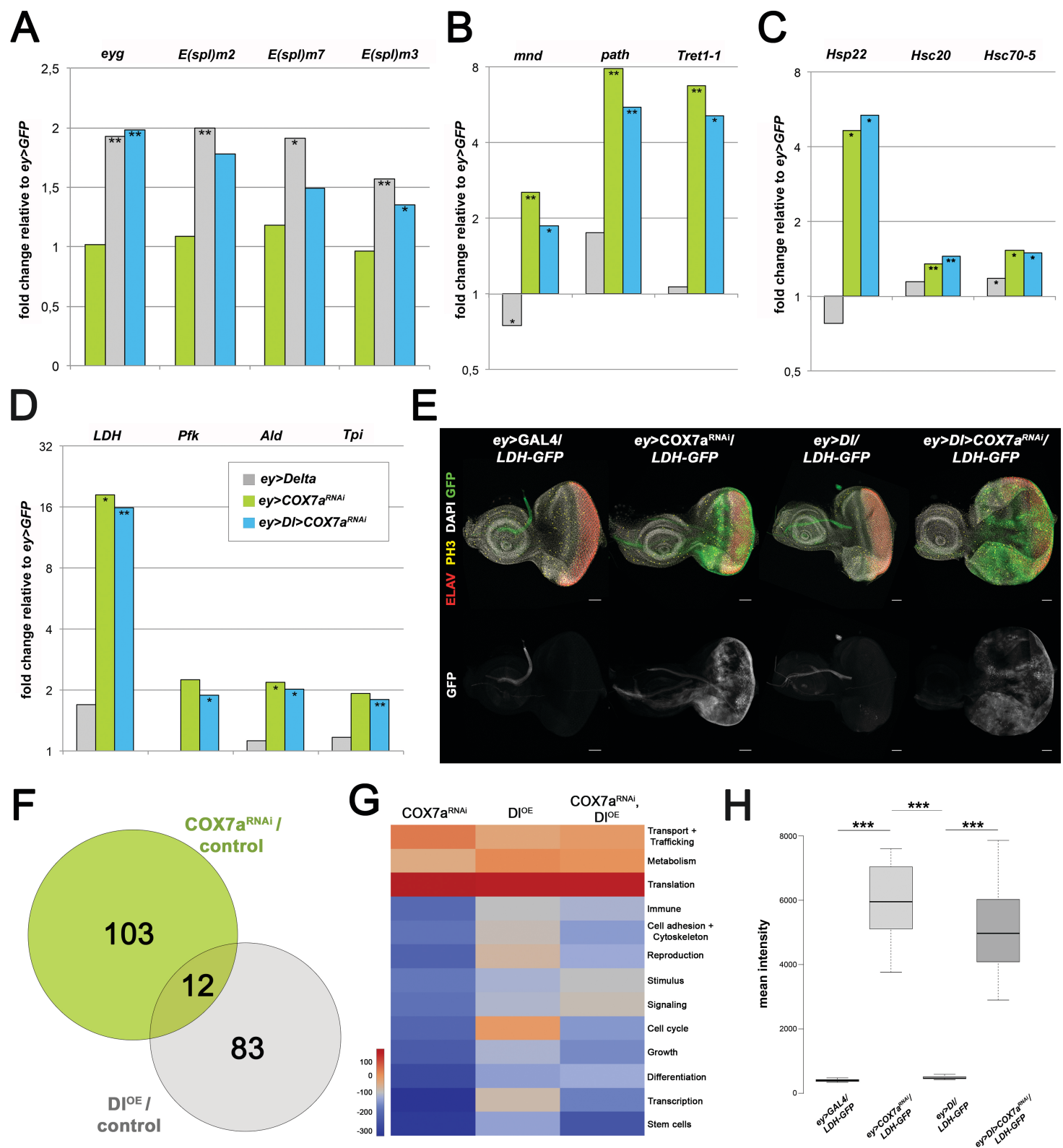

Figure 2: ETC impairment and Notch over-activation cause different nuclear responses.

A-D Fold change of selected target genes of the Notch pathway (A), nutrient transporters (B), mitochondrial chaperones (C) and glycolytic enzymes (D) shown in the respective genotypes relative to ey>GFP control. Asterisks indicate significance of fold-change to ey>GFP $\left({ }^{*}=\right.$ $\left.p<0,05 ;{ }^{* *}=p<0,01\right)$.

E Sum-projection of late L3 eye-antennal discs stained for ELAV (red, labelling photoreceptor clusters), phospho-Histone 3 (PH3) (yellow, labelling mitotic cells), DAPI (white, labelling nuclei) and carrying the $L D H$-GFP (green) enhancer trap. Larvae were reared at $25^{\circ} \mathrm{C}$ on standard fly 
bioRxiv preprint doi: https://doi.org/10.1101/425744; this version posted September 24, 2018. The copyright holder for this preprint (which was not certified by peer review) is the author/funder, who has granted bioRxiv a license to display the preprint in perpetuity. It is made available under aCC-BY-NC-ND 4.0 International license.

food. Control (ey-GAL4) or $D I^{O E}$ discs did not express any detectable GFP. COX7a ${ }^{R N A i}$ induced GFP transcription primarily in progenitor cells.

F Venn diagram showing that $C O X 7 a^{R N A i}$ and $D I^{O E}$ induced primarily distinct sets of target genes (fold $>1,5 ; p<0,05$ ).

G Heat-map displaying presence of genes belonging to higher-order categories in genetic backgrounds. The different representation of GO term categories reflects the different transcriptional responses induced by $\operatorname{COX} 7 a^{R N A i}$ and $D I^{O E}$. The colour range corresponds to the delta rank of genes annotated to the category that also appear in the sample: red colour represents enrichment of higher-expressed genes, blue colours categories enriched with lowerexpressed genes. Rows are hierarchically clustered using Euclidean distance with complete linkage.

H Quantification of LDH-GFP signal of larval discs as shown in $E(n=6)$. Asterisks indicate $p$ value according to unpaired t-test: ${ }^{*} p<0,05 ;{ }^{* *} p<0,01 ;{ }^{* * *} p<0,001$.

Anterior is to the left, dorsal is up, scale bar represents $50 \mu \mathrm{m}$ in all microscope images. See also Fig S2. 
bioRxiv preprint doi: https://doi.org/10.1101/425744; this version posted September 24, 2018. The copyright holder for this preprint (which was not certified by peer review) is the author/funder, who has granted bioRxiv a license to display the preprint in perpetuity. It is made available under aCC-BY-NC-ND 4.0 International license.

A

iRegulon analysis:

\begin{tabular}{l|c|c|c} 
NES & Name & Targets & Motif \\
\hline 9,925 & hATF4 (taipale) & $22 / 114$ \\
8,575 & mES cMyc (homer) & $15 / 114$ \\
8,257 & mAtf4 (taipale) & $15 / 114$ \\
7,240 & dATF4-Irbp18 (flyfactor) & $16 / 114$
\end{tabular}

C

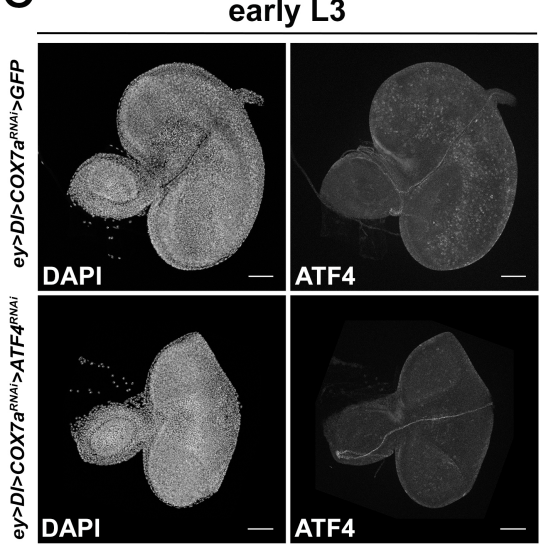

D

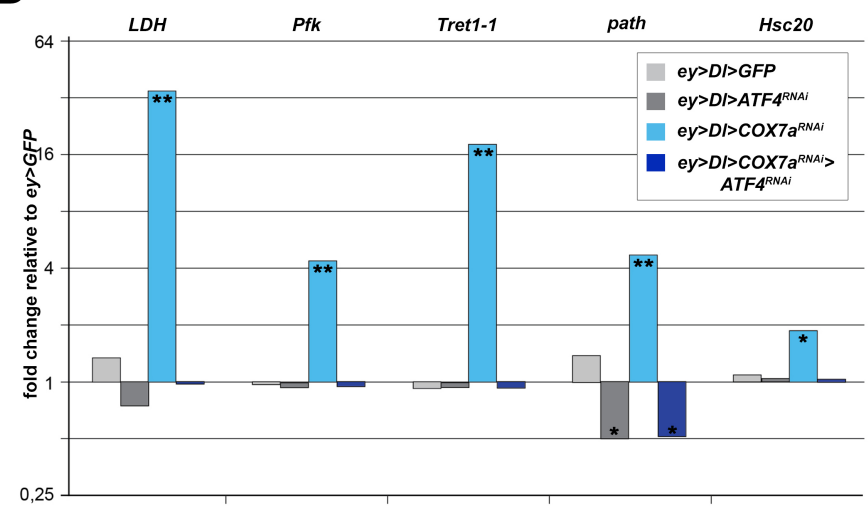

F
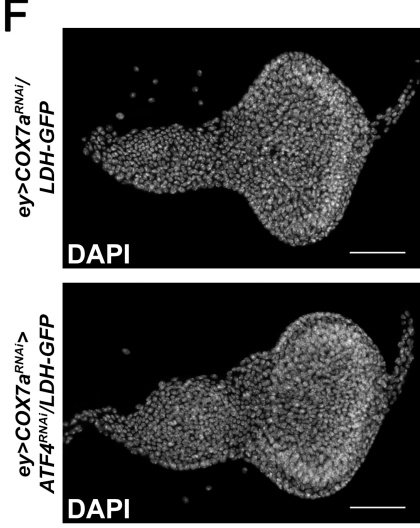

B

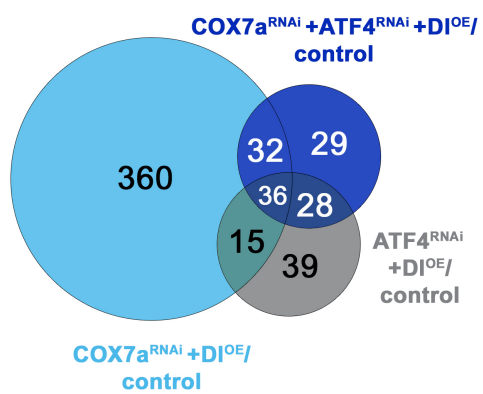

late L3
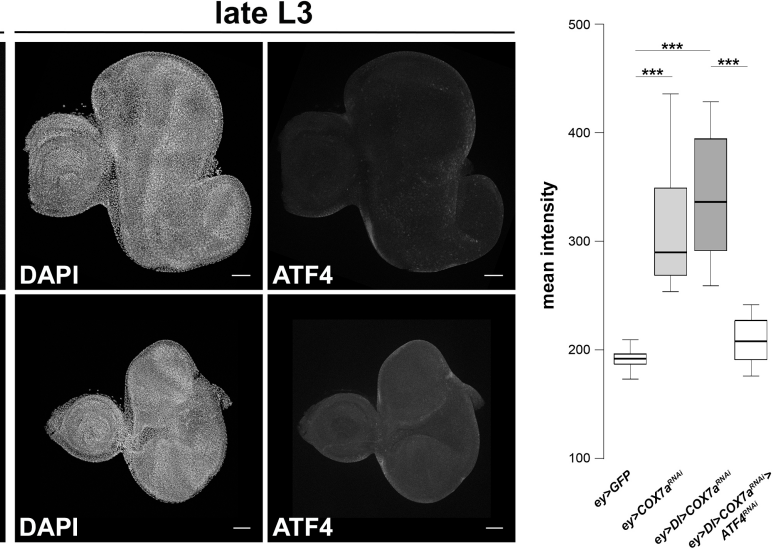

$E^{100}$

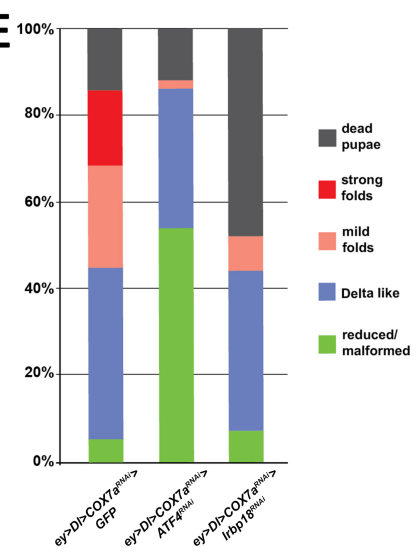

G

Figure 3: PERK-ATF4 mediate nuclear response of ETC impairment. 
A Highest ranking transcription factor motifs according to iRegulon analysis under standard settings (9713 PWMs; 5kb upstream, 5'-UTR and $1^{\text {st }}$ intron with standard cut-offs). The human ATF4 motif was the highest-ranking motif, followed by a cMyc motif (that is a near-identical reverse-complement of the hATF4 motif), mouse Atf4 and a Drosophila heterodimer of ATF4 and Irbp18.

B Venn diagram depicting dependency of $D I^{O E}$, COX $7 a^{R N A i}$ induced target genes on ATF4 function. For this microarray analysis, larvae were reared at $25^{\circ} \mathrm{C}$ on nutrient restriction food. The majority of $D I^{O E}, C O X 7 a^{R N A i}$ induced target genes (360/443) were not induced in $D I^{O E}$,

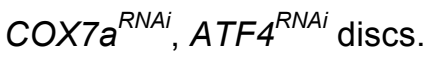

C Sum-projection of early or late L3 eye-antennal discs stained for DAPI (labelling nuclei) and ATF4. Larvae were reared at $25^{\circ} \mathrm{C}$ on nutrient restriction food. ATF4 was detected in early L3 progenitors, but not in late L3 discs. ATF4 ${ }^{\text {RNAi }}$ abolished ATF4 protein induction and overproliferation. Quantification (to the right) of ATF4 signal in early L3 eye discs of these genotypes and the ones of Figure S3A. Asterisks indicate $p$-value according to unpaired t-test: * $p<0,05 ;{ }^{* *}$ $p<0,01 ;{ }^{* * *} p<0,001$.

D Fold change of selected $\operatorname{COX} 7 a^{R N A i}$-induced genes in the Delta ${ }^{O E}$ background (relative to ey>GFP control) according to second microarray analysis under nutrient restriction. Induction of these genes in response to $C O X 7 a^{R N A i}$ requires ATF4 function. Asterisks indicate significance of fold-change to ey>GFP $\left({ }^{*}=p<0,05 ;{ }^{* *}=p<0,01\right)$.

E Quantification of adult eye phenotypes in crosses of ey>DI ${ }^{O E}, C O X 7 a^{R N A i}$ females with either UAS-GFP (control), ATF4 $4^{R N A i}$ or Irbp $18^{R N A i}$ males. Larvae were reared at $25^{\circ} \mathrm{C}$ on nutrient restriction food. Knockdown of ATF4 and its cofactor Irbp18 repressed over-proliferation.

F Sum-projection and quantification of LDH-GFP signal in early L3 eye-antenna discs. In the absence of ATF4 function, LDH-GFP is not detectable (as in controls). Quantification (to the right) of GFP signal in early L3 eye discs of these genotypes. Asterisks indicate p-value according to unpaired t-test: ${ }^{*} p<0,05 ;{ }^{* *} p<0,01 ;{ }^{* * *} p<0,001$.

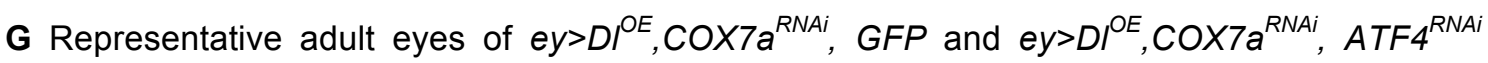
flies, showing that $C O X 7 a^{R N A i}$-mediated over-proliferation requires ATF4. 
bioRxiv preprint doi: https://doi.org/10.1101/425744: this version posted September 24,2018 . The copyriaht holder for this preprint (which was not certified by peer review) is the author/funder, who has granted bioRxiv a license to display the preprint in perpetuity. It is made available under aCC-BY-NC-ND 4.0 International license.

Anterior is to the left, dorsal is up, scale bar represents $50 \mu \mathrm{m}$ in all microscope images. See also Figure S3. 


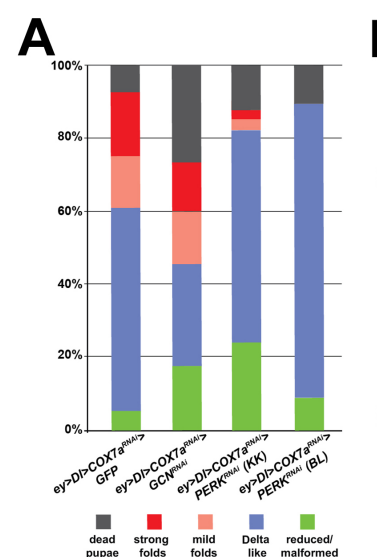

B
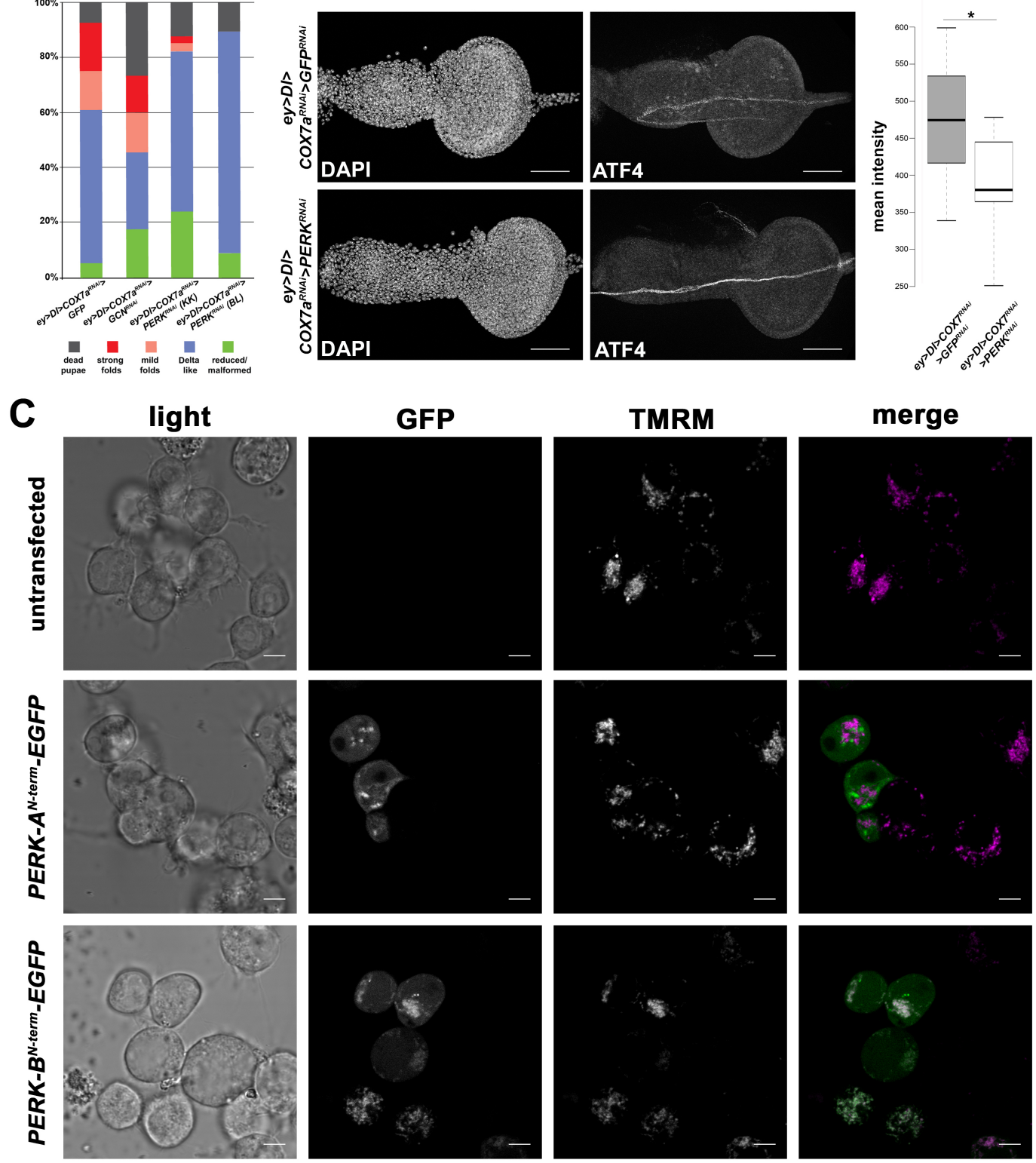

Figure 4: A mitochondria-targeted PERK isoform mediates ATF4 activation

A Quantification of adult eye phenotypes in crosses of ey>DI ${ }^{O E}, C O X 7 a^{R N A i}$ females with either UAS-GFP (control), GCN2 ${ }^{R N A i}, A T F 4^{R N A i}$ or two different PERK ${ }^{R N A i}$ males. Larvae were reared at $25^{\circ} \mathrm{C}$ on nutrient restriction food. While knockdown of GCN2 failed to abolish overgrown eyes, both $P E R K^{R N A i}$ constructs repressed over-proliferation as did $A T F 4^{R N A i}$.

B Max-projection of late L2 eye-antennal discs stained for DAPI and ATF4. Larvae were reared at $25^{\circ} \mathrm{C}$ on nutrient restriction food. Knock-down of PERK abolished any detectable ATF4 protein in $\mathrm{DI}^{\mathrm{OE}}, \mathrm{COX} 7 \mathrm{a}^{\mathrm{RNAi}}$ animals. Quantification (to the right) of GFP signal in early $\mathrm{L} 3$ eye discs of these genotypes. Asterisks indicate $p$-value according to unpaired t-test: ${ }^{*} p<0,05 ;{ }^{*}$ 
bioRxiv preprint doi: https://doi.org/10.1101/425744; this version posted September 24,2018 . The copyright holder for this preprint (which

was not certified by peer review) is the author/funder, who has granted bioRxiv a license to display the preprint in perpetuity. It is made available under aCC-BY-NC-ND 4.0 International license.

$p<0,01 ;{ }^{* * *} p<0,001$. Anterior is to the left, dorsal is up, scale bar represents $50 \mu \mathrm{m}$ in microscope images.

C Confocal single plane images of Drosophila S2R+ cells labelled with the mitochondrial dye TMRM. TMRM labelling highlights filamentous mitochondria in these cells. PERK-B ${ }^{\mathrm{N} \text {-term }}$-EGFP is detected primarily in mitochondria, while PERK-A ${ }^{\mathrm{N}-\mathrm{term}^{-}}$-GFP was found to be primarily excluded from mitochondria. Scale bar represents $5 \mu \mathrm{m}$.

See also Fig S4. 
A
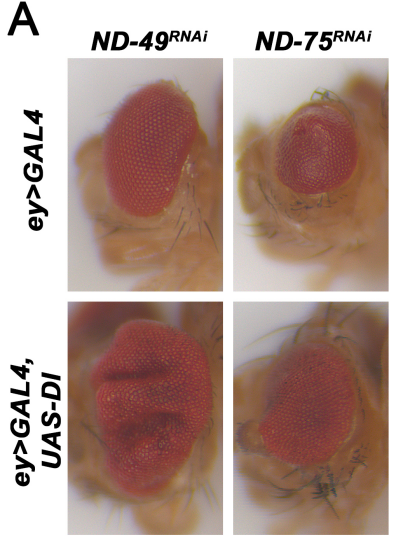

C

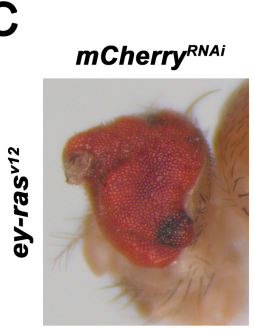

D

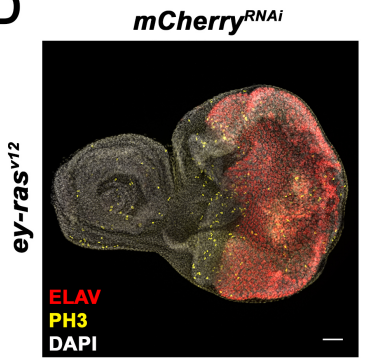

UQCR

UQCR-QRAT COX5a $\mathbf{Q}^{R N A i}$

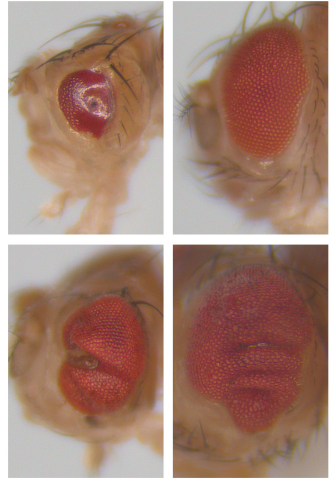

COX7a $a^{\text {RNAi, }}$ ATF4 $^{\text {RAA }}$
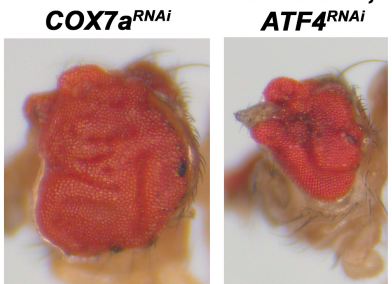

$\operatorname{coX7a^{RNAi}}$

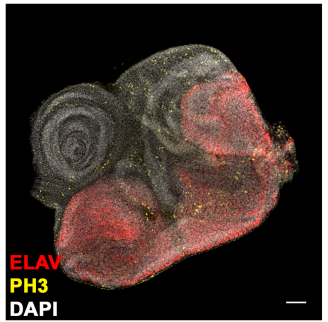

B

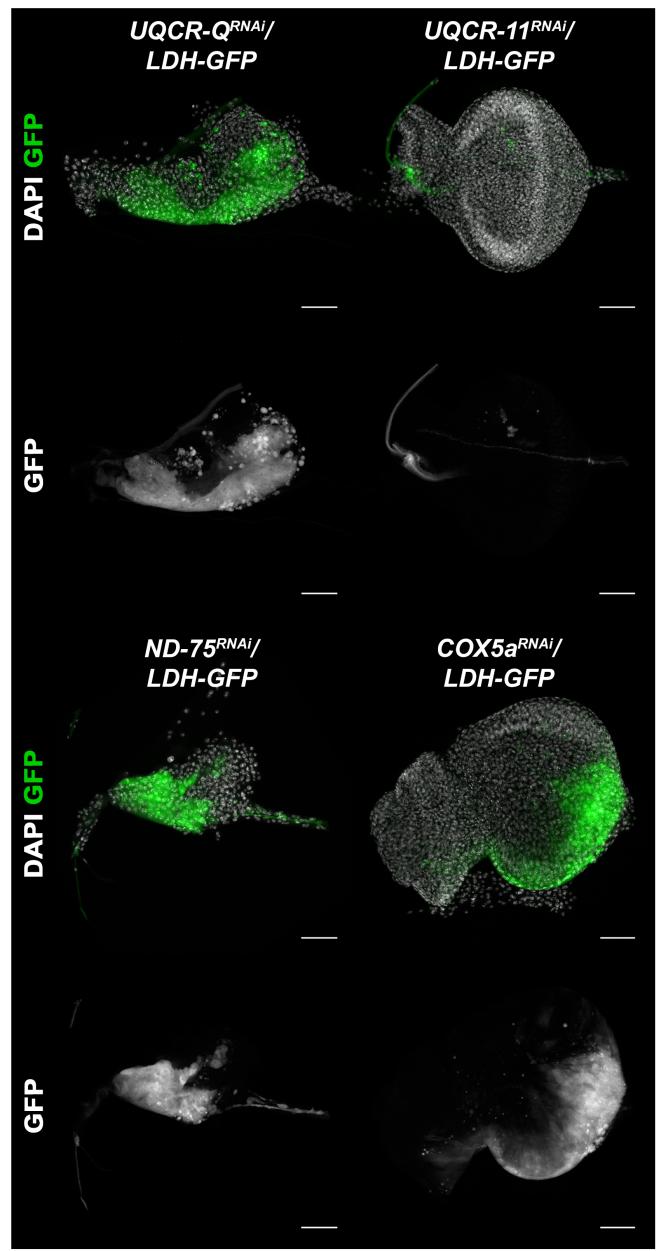

Figure 5: ATF4-mediated over-proliferation is a common cooperation of ETC knockdown and oncogenic signalling.

A Adult eye phenotypes recovered upon knock-down of ETC subunits with either ey-GAL4 (upper row) or in the background of $\mathrm{DI}^{\mathrm{OE}}$ (lower row). ND-49 and COX5a caused slightly reduced eye size when individually knocked down (upper row) and over-proliferation with $\mathrm{DI}^{\mathrm{OE}}$. The strongly disturbed development in ND-75 or UQCR-Q knock-down eyes could not be transformed into over-proliferation by $\mathrm{DI}^{\mathrm{OE}}$.

B Sum-projection of early L3 eye-antennal discs stained for DAPI (white, labelling nuclei) and showing GFP fluorescence of the $L D H$-GFP enhancer trap. The $L D H$-GFP reporter was induced upon knock-down of the indicated ETC subunits in varying strengths. Complex 3 subunit UQCR11 did not induce GFP. 
bioRxiv preprint doi: https://doi.org/10.1101/425744; this version posted September 24, 2018. The copyright holder for this preprint (which was not certified by peer review) is the author/funder, who has granted bioRxiv a license to display the preprint in perpetuity. It is made available under aCC-BY-NC-ND 4.0 International license.

C Adult eye phenotypes recovered upon COX7a knock-down in the background of ras ${ }^{\mathrm{v} 12}$ overexpression. In control knock-down $\left(\mathrm{mCherry}^{\mathrm{RNAi}}\right.$ ), eyes were slightly folded and often contained a characteristic dorsal-anterior outgrowth of eye and cuticle. COX7a ${ }^{\mathrm{RNAi}}$ induced massive tissue folding, in an ATF4-dependent manner.

D Sum-projection of late L3 eye-antenna discs stained for DAPI (white, labelling nuclei), ELAV (red, labelling photoreceptors) and phospho-Histone 3 (PH3) (yellow, labelling cells in mitosis). COX7a knock-down in the ras ${ }^{\mathrm{v} 12}$ over-expression background increased disc size and tissue folding.

Anterior is to the left, dorsal is up, scale bar represents $50 \mu \mathrm{m}$ in all microscope images. See also Fig S5. 


\section{References}

[1] Warburg O, Posener K, Negelein E. On the metabolism of carcinoma cells. Biochemische Zeitschrift 1924;152:309-44.

[2] Koppenol WH, Bounds PL, Dang CV. Otto Warburg's contributions to current concepts of cancer metabolism. Nat Rev Cancer 2011;11:325-37. doi:10.1038/nrc3038.

[3] Vander Heiden MG, Cantley LC, Thompson CB. Understanding the Warburg effect: the metabolic requirements of cell proliferation. Science 2009;324:1029-33. doi:10.1126/science.1160809.

[4] Vogelstein B, Papadopoulos N, Velculescu VE, Zhou S, Diaz LAJ, Kinzler KW. Cancer Genome Landscapes. Science 2013;339:1546-58. doi:10.1126/science.1235122.

[5] Mandal S, Guptan P, Owusu-Ansah E, Banerjee U. Mitochondrial Regulation of Cell Cycle Progression during Development as Revealed by the tenured Mutation in Drosophila. Developmental Cell 2005;9:843-54. doi:10.1016/j.devcel.2005.11.006.

[6] Owusu-Ansah E, Yavari A, Mandal S, Banerjee U. Distinct mitochondrial retrograde signals control the G1-S cell cycle checkpoint. Nature Genetics 2008;40:356-61. doi:10.1038/ng.2007.50.

[7] Ohsawa S, Sato Y, Enomoto M, Nakamura M, Betsumiya A, Igaki T. Mitochondrial defect drives non-autonomous tumour progression through Hippo signalling in Drosophila. Nature 2013;490:547-51. doi:10.1038/nature11452.

[8] Nowak K, Seisenbacher G, Hafen E, Stocker H. Nutrient restriction enhances the proliferative potential of cells lacking the tumor suppressor PTEN in mitotic tissues. eLife 2013;2:e00380-21. doi:10.7554/eLife.00380.

[9] Zhai Z, Ha N, Papagiannouli F, Hamacher-Brady A, Brady N, Sorge S, et al. Antagonistic Regulation of Apoptosis and Differentiation by the Cut Transcription Factor Represents a Tumor-Suppressing Mechanism in Drosophila. PLoS Genet 2012;8:e1002582. doi:10.1371/journal.pgen.1002582.

[10] Dominguez M, de Celis JF. A dorsal/ventral boundary established by Notch controls growth and polarity in the Drosophila eye. Nature 1998.

[11] Kemppainen KK, Rinne J, Sriram A, Lakanmaa M, Zeb A, Tuomela T, et al. Expression of alternative oxidase in Drosophila ameliorates diverse phenotypes due to cytochrome oxidase deficiency. Human Molecular Genetics 2013;23:2078-93. doi:10.1093/hmg/ddt601.

[12] Hay BA, Wolff T, Rubin GM. Expression of Baculovirus P35 Prevents Cell-Death in Drosophila. Development 1994;120:2121-9.

[13] Bray SJ. Notch signalling: a simple pathway becomes complex. Nat Rev Mol Cell Biol 2006;7:678-89. doi:10.1038/nrm2009.

[14] Wang CW, Purkayastha A, Jones KT, Thaker SK, Banerjee U. In vivo genetic dissection of tumor growth and the Warburg effect. elife 2016;5. doi:10.7554/eLife.18126.

[15] Janky R, Verfaillie A, Imrichová H, Van de Sande B, Standaert L, Christiaens V, et al. iRegulon: From a Gene List to a Gene Regulatory Network Using Large Motif and Track Collections. PLoS Comput Biol 2014;10:e1003731-19. doi:10.1371/journal.pcbi.1003731.

[16] Lee JE, Oney M, Frizzell K, Phadnis N, Hollien J. Drosophila melanogaster activating transcription factor 4 regulates glycolysis during endoplasmic reticulum stress. G3 (Bethesda) 2015;5:667-75. doi:10.1534/g3.115.017269.

[17] Lee J-I, Dominy JE Jr., Sikalidis AK, Hirschberger LL, Wang W, Stipanuk MH. HepG2/C3A cells respond to cysteine deprivation by induction of the amino acid deprivation/integrated stress response pathway. Physiological Genomics 2008;33:21829. doi:10.1152/physiolgenomics.00263.2007.

[18] Kang M-J, Vasudevan D, Kang K, Kim K, Park J-E, Zhang N, et al. 4E-BP is a target of the GCN2-ATF4 pathway during Drosophiladevelopment and aging. The Journal of Cell Biology 2017;216:115-29. doi:10.1083/jcb.201511073.

[19] Reinke AW, Baek J, Ashenberg O, Keating AE. Networks of bZIP protein-protein interactions diversified over a billion years of evolution. Science 2013;340:730-4. doi:10.1126/science.1233465.

[20] Huggins CJ, Mayekar MK, Martin N, Saylor KL, Gonit M, Jailwala P, et al. C/EBPy Is a 

15.

Critical Regulator of Cellular Stress Response Networks through Heterodimerization with ATF4. Molecular and Cellular Biology 2015;36:693-713. doi:10.1128/MCB.00911-

[21] Goberdhan DCl, Meredith D, Boyd CAR, Wilson C. PAT-related amino acid transporters regulate growth via a novel mechanism that does not require bulk transport of amino acids. Development 2005;132:2365-75. doi:10.1242/dev.01821.

[22] Harding HP, Novoa I, Zhang YH, Zeng HQ, Wek R, Schapira M, et al. Regulated translation initiation controls stress-induced gene expression in mammalian cells. Molecular Cell 2000;6:1099-108.

[23] Harding HP, Zhang YH, Ron D. Protein translation and folding are coupled by an endoplasmic-reticulum-resident kinase. Nature 1999;397:271-4. doi:10.1038/16729.

[24] Yamamoto K, Sato T, Matsui T, Sato M, Okada T, Yoshida H, et al. Transcriptional Induction of Mammalian ER Quality Control Proteins Is Mediated by Single or Combined Action of ATF6 $\alpha$ and XBP1. Developmental Cell 2007;13:365-76. doi:10.1016/j.devcel.2007.07.018.

[25] Ryoo HD, Domingos PM, Kang M-J, Steller $H$. Unfolded protein response in a Drosophila model for retinal degeneration. Embo J 2007;26:242-52. doi:10.1038/sj.emboj.7601477.

[26] Claros MG, Vincens P. Computational method to predict mitochondrially imported proteins and their targeting sequences. Eur J Biochem 1996;241:779-86.

[27] Capon DJ, Seeburg PH, McGrath JP, Hayflick JS, Edman U, Levinson AD, et al. Activation of Ki-Ras 2 Gene in Human-Colon and Lung Carcinomas by 2 Different Point Mutations. Nature 1983;304:507-13.

[28] Birsoy K, Wang T, Chen WW, Freinkman E, Abu-Remaileh M, Sabatini DM. An Essential Role of the Mitochondrial Electron Transport Chain in Cell Proliferation Is to Enable Aspartate Synthesis. Cell 2015;162:540-51. doi:10.1016/j.cell.2015.07.016.

[29] Sullivan LB, Gui DY, Hosios AM, Bush LN, Freinkman E, Vander Heiden MG. Supporting Aspartate Biosynthesis Is an Essential Function of Respiration in Proliferating Cells. Cell 2015;162:552-63. doi:10.1016/j.cell.2015.07.017.

[30] Kilberg MS, Shan J, Su N. ATF4-dependent transcription mediates signaling of amino acid limitation. Trends in Endocrinology \& Metabolism 2009;20:436-43. doi:10.1016/j.tem.2009.05.008.

[31] Quirós PM, Prado MA, Zamboni N, D’Amico D, Williams RW, Finley D, et al. Multiomics analysis identifies ATF4 as a key regulator of the mitochondrial stress response in mammals. The Journal of Cell Biology 2017;216:2027-45. doi:10.1083/jcb.201702058.

[32] Celardo I, Costa AC, Lehmann S, Jones C, Wood N, Mencacci NE, et al. Mitofusinmediated ER stress triggers neurodegeneration in pink1/parkin models of Parkinson's disease. Cell Death Dis 2016;7:e2271-1. doi:10.1038/cddis.2016.173.

[33] Nargund AM, Pellegrino MW, Fiorese CJ, Baker BM, Haynes CM. Mitochondrial Import Efficiency of ATFS-1 Regulates Mitochondrial UPR Activation. Science 2012;337:58790. doi:10.1126/science.1223560.

[34] Fiorese CJ, Schulz AM, Lin Y-F, Rosin N, Pellegrino MW, Haynes CM. The Transcription Factor ATF5 Mediates a Mammalian Mitochondrial UPR. Curbio 2016;26:2037-43. doi:10.1016/j.cub.2016.06.002.

[35] Bao XR, Ong S-E, Goldberger O, Peng J, Sharma R, Thompson DA, et al. Mitochondrial dysfunction remodels one-carbon metabolism in human cells. eLife 2016;5:1910. doi:10.7554/eLife.10575.

[36] Yoneda T, Benedetti C, Urano F, Clark SG, Harding HP, Ron D. Compartment-specific perturbation of protein handling activates genes encoding mitochondrial chaperones. J Cell Sci 2004;117:4055-66. doi:10.1242/jcs.01275.

[37] Djiane A, Krejci A, Bernard FEDER, Fexova S, Millen K, Bray SJ. Dissecting the mechanisms of Notch induced hyperplasia. Embo J 2012;32:60-71. doi:10.1038/emboj.2012.326.

[38] Hockel M, Vaupel P. Tumor hypoxia: Definitions and current clinical, biologic, and molecular aspects. J Natl Cancer Inst 2001;93:266-76.

[39] Liou G-Y, Storz P. Reactive oxygen species in cancer. Free Radical Research 2010;44:479-96. doi:10.3109/10715761003667554. 
[40] Wouters BG, Koritzinsky M. Hypoxia signalling through mTOR and the unfolded protein response in cancer. Nat Rev Cancer 2008;8:851-64. doi:10.1038/nrc2501.

[41] Singleton DC, Harris AL. Targeting the ATF4 pathway in cancer therapy. Expert Opinion on Therapeutic Targets 2012;16:1189-202. doi:10.1517/14728222.2012.728207.

[42] Li J-R, Sun C-H, Li W, Chao R-F, Huang C-C, Zhou XJ, et al. Cancer RNA-Seq Nexus: a database of phenotype-specific transcriptome profiling in cancer cells. Nucleic Acids Res 2016;44:D944-51. doi:10.1093/nar/gkv1282.

[43] Uhlen M, Zhang C, Lee S, Sjöstedt E, Fagerberg L, Bidkhori G, et al. A pathology atlas of the human cancer transcriptome. Science 2017;357:eaan2507-13. doi:10.1126/science.aan2507.

[44] Chatterjee N, Bohmann D. A Versatile $\Phi$ C31 Based Reporter System for Measuring AP-1 and Nrf2 Signaling in Drosophila and in Tissue Culture. PLoS ONE 2012;7:e34063-9. doi:10.1371/journal.pone.0034063.

[45] Weger BD, Weger M, Görling B, Schink A, Gobet C, Keime C, et al. Extensive Regulation of Diurnal Transcription and Metabolism by Glucocorticoids. PLoS Genet 2016;12:e1006512-24. doi:10.1371/journal.pgen.1006512.

[46] Wirtz M, Droux M, Hell R. O-acetylserine (thiol) lyase: an enigmatic enzyme of plant cysteine biosynthesis revisited in Arabidopsis thaliana. J Exp Bot 2004;55:1785-98. doi:10.1093/jxb/erh201.

[47] Uran S, Landmark KE, Hjellum G, Skotland T. Quantification of 13C pyruvate and 13C lactate in dog blood by reversed-phase liquid chromatography-electrospray ionization mass spectrometry after derivatization with 3-nitrophenylhydrazine. Journal of Pharmaceutical and Biomedical Analysis 2007;44:947-54. doi:10.1016/j.jpba.2007.04.001. 